\title{
蛙ノ色素細胞二關スル實驗
}

\section{II. 二三藥物，影響}

大學院學生 醫學士 小林 㿽 三

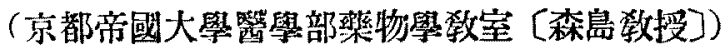

（昭和二年六月十三日受付）

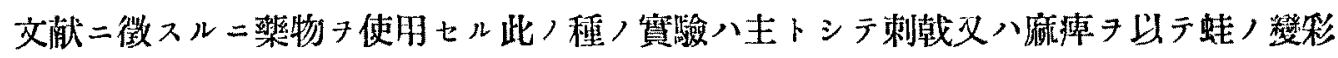

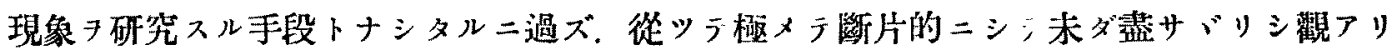
シカ，最近當呚室二於テ小原 ${ }^{7}$ 塚本 ${ }^{9}$ ) 氏等八各種ノ藥物二就テ系統的ニ多ク，實驗キ行 ヘリ。余ハ三三藥物二就テ併用賽驗 試にタリ。

\section{實騟材料及方法}

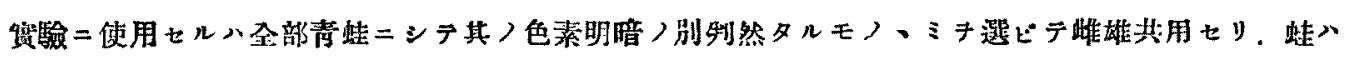

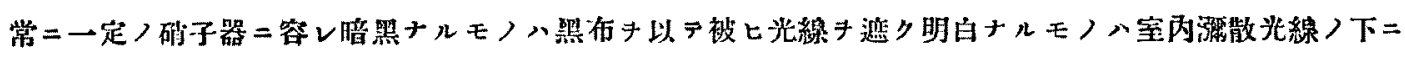

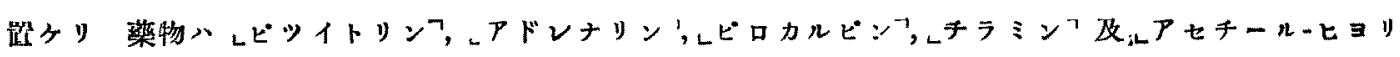

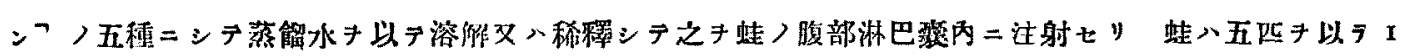

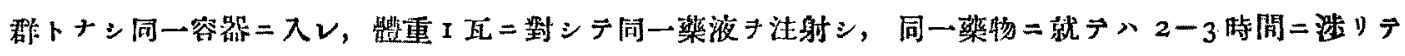

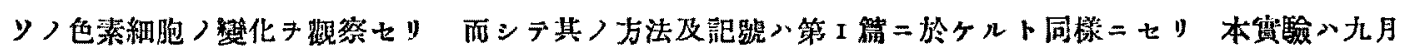
凡 $23^{\circ} \mathrm{C}$ ノ室温二於テ行へリ

\section{實 驗 成 樍}

\section{1. เピツイトリンフ 及 アアドレナリン}

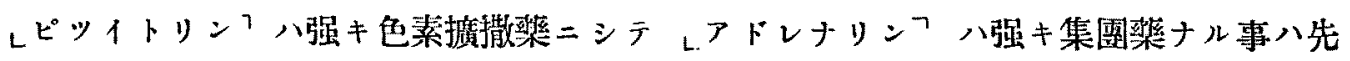

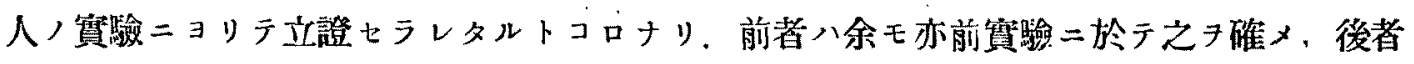

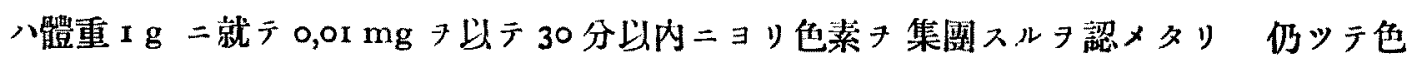




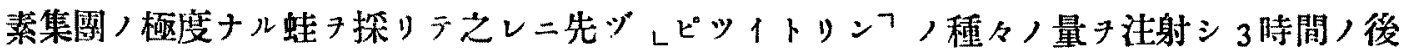
レアドレナリンフ 7 體重 $\mathbf{I} \mathrm{g}=$ 就キ 0,01 $\mathrm{mg}$ 注射七リ。

第 1 表

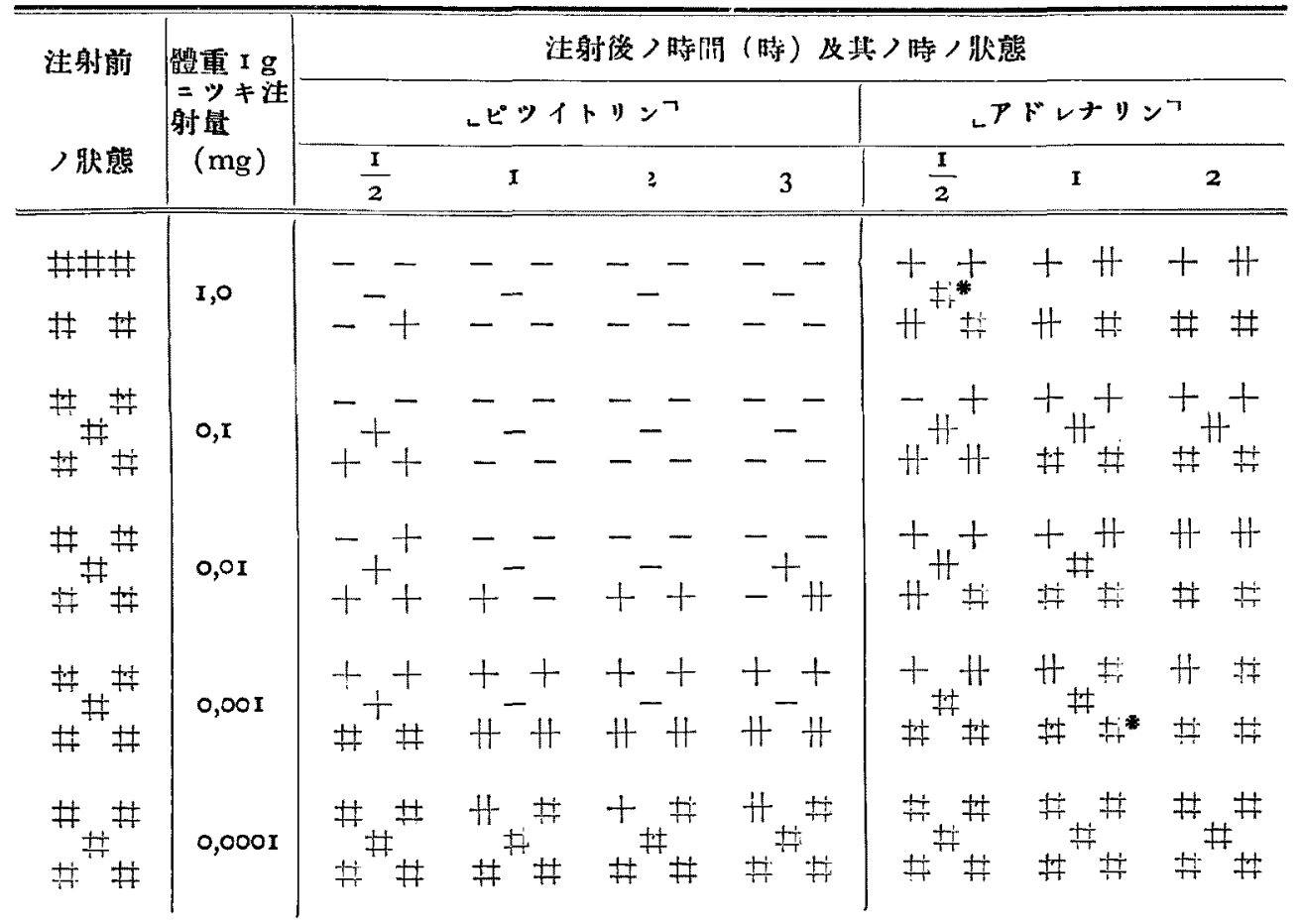

表中*タ附ンタルモノハ死七ルモノニシテ以下除ク

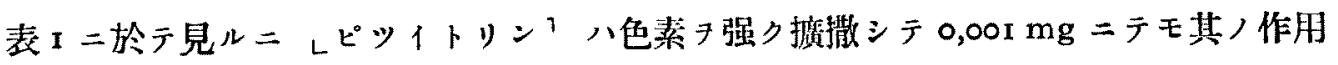
著明ナリ 0 , $0001 \mathrm{mg}$ チ注射七ルモノニアリテハ最早其ノ作用明ナラズ. え二レアドレナ リンフノ有効量キ作用セシムル時ハ再ビ集團キ來ス。

\section{2. เピロカルピンフ 及 レアセチール-ヒヨリンフ}

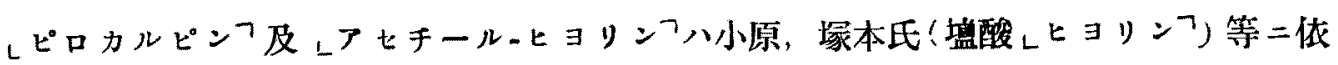
リテ何レモ色素ノ集團セラル、モノナル事知ラレタリ.余モ亦之ヨ追試シテ其ノ各 $0,1 \mathrm{mg}$

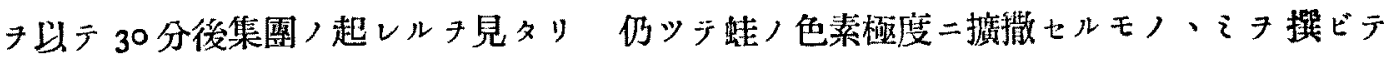

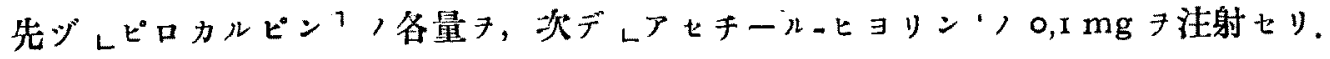


第 2 表

\begin{tabular}{|c|c|c|c|c|c|c|c|c|}
\hline \multirow{3}{*}{ 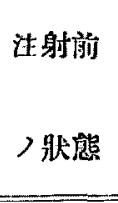 } & \multirow{3}{*}{ 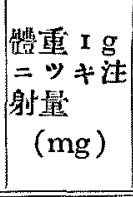 } & \multicolumn{7}{|c|}{ 淮射㷋八時間（時）仅其八時／狀態 } \\
\hline & & \multicolumn{4}{|c|}{ レビロカルビンᄀ } & \multicolumn{3}{|c|}{ レアセチールーヒョบンフ } \\
\hline & & $\frac{I}{2}$ & I & 2 & 3 & $\frac{I}{2}$ & I & 2 \\
\hline-- & $\mathrm{I}, \mathrm{O}$ & $\begin{array}{l}H+ \\
H^{H}+\end{array}$ & $\begin{array}{l}H \\
H^{H}+\end{array}$ & ${ }_{+i}^{+t_{i}^{+}}+$ & $\ddot{H}_{+}^{\#}$ & $\begin{array}{l}H+4 \\
H^{+4}+\end{array}$ & $\begin{array}{l}\#+{ }^{H} \\
+\end{array}$ & $\begin{array}{l}H+ \\
t^{+}+\end{array}$ \\
\hline${ }_{-}^{-}-$ & $0, \mathrm{I}$ & $H^{+H}+$ & $H^{\#}+\#$ & $H^{+H}$ & $\begin{array}{l}+\forall \\
+\because \#\end{array}$ & $\begin{array}{l}+H \\
+H\end{array}$ & 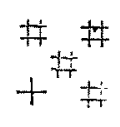 & 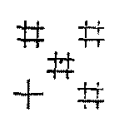 \\
\hline${ }^{-}-$ & 0,01 & $H^{+}{ }^{+}$ & $t^{\#+}$ & $\begin{array}{c}-\frac{+}{+r} \\
\dot{t r}^{+}\end{array}$ & $\begin{array}{l}H^{\#} \\
H^{+}\end{array}$ & $H^{\#}$ & $\begin{array}{l}+H \\
H^{+t}\end{array}$ & $t_{+t}^{+t}$ \\
\hline-- & 0,001 & $+^{-}-$ & $t^{+}+$ & $+^{-1}+$ & -+ & $\begin{array}{l}-+ \\
+4\end{array}$ & $\mathrm{H}^{+}+$ & $H_{+}^{+}+$ \\
\hline-- & 0,0001 & -- & $-{ }^{-}-$ & ${ }^{-}-$ & -- & ${ }_{-}^{+}-$ & $\begin{array}{l}+-- \\
+H\end{array}$ & ${ }_{+}^{+}+$ \\
\hline
\end{tabular}

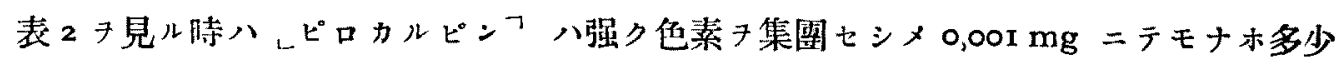

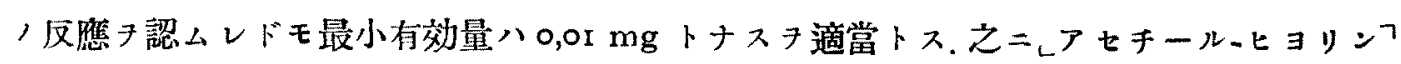

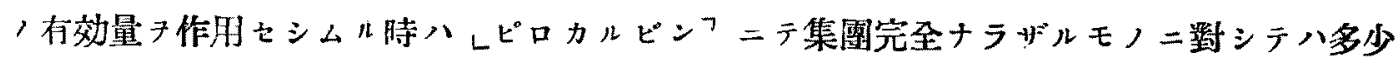
, 反應キ見ル

\section{3. ᄂチラミンフ及 とピロカルピン}

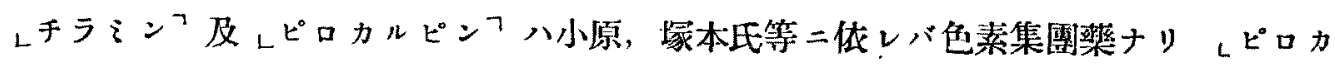

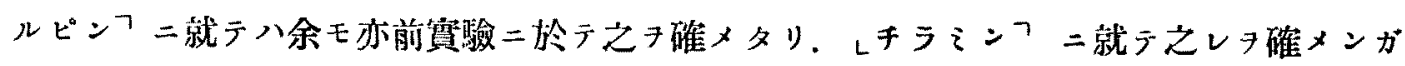

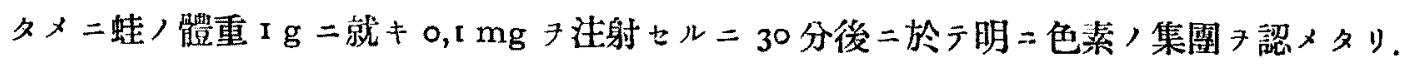

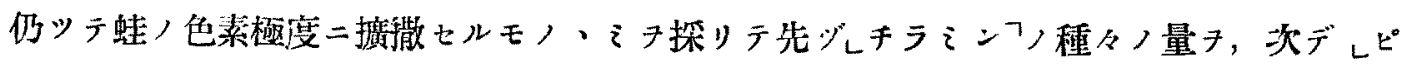
ロカルピンフ， O, I mg フ注射セり(第 3 表參照).

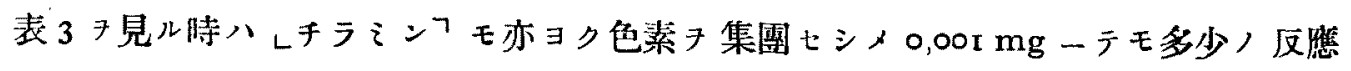

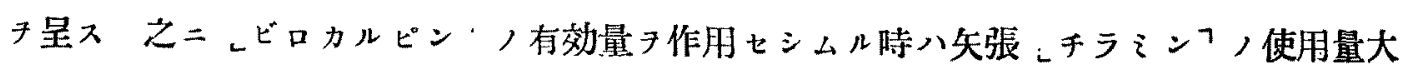

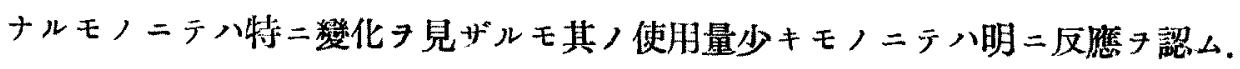




\begin{tabular}{|c|c|c|c|c|c|c|c|c|}
\hline \multirow{3}{*}{$\begin{array}{l}\text { 注射前 } \\
\text { つ爿㮩 }\end{array}$} & \multirow{3}{*}{ 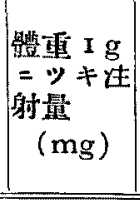 } & \multicolumn{7}{|c|}{ 注射啳〉時間 (洔) 及其〉時〉㹜鷾 } \\
\hline & & \multicolumn{4}{|c|}{ レチラミンา } & \multicolumn{3}{|c|}{ レビロガルビンフ } \\
\hline & & $\frac{\mathrm{I}}{2}$ & I & 2 & 3 & $\frac{I}{2}$ & $\mathbf{I}$ & 2 \\
\hline-- & 1,0 & $H^{H}+{ }_{i}^{H}$ & 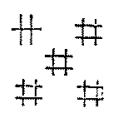 & $H^{H}$ & $\begin{array}{l}\text { Hit } \\
H^{+4}+4\end{array}$ & $\underbrace{+t}_{+}$ & $\begin{array}{l}H+H \\
H \\
H\end{array}$ & $\begin{array}{l}H \\
H\end{array}$ \\
\hline-- & $0, \mathbf{I}$ & ${ }_{H}^{H}+$ & $\begin{array}{l}+H \\
t^{\#}\end{array}$ & 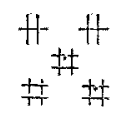 & 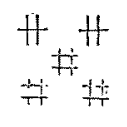 & $\begin{array}{l}+H \\
t^{+1}+1\end{array}$ & 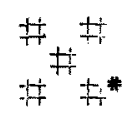 & ${ }_{H}^{\#}$ \\
\hline-- & 0,01 & $H^{+}+$ & 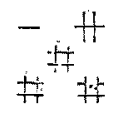 & 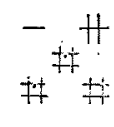 & $\begin{array}{l}+t \\
+\frac{1}{4}+\end{array}$ & $\begin{array}{l}+H \\
+H\end{array}$ & $\begin{array}{l}+t \\
+t\end{array}$ & ${ }_{\#+\#}^{\#} \#$ \\
\hline${ }^{-}-$ & 0,001 & +- & $\begin{array}{l}-- \\
+4\end{array}$ & ${ }^{-}-$ & $\frac{-1}{H-H}$ & ${ }_{\#}^{\#}+{ }^{H}$ & ${ }_{\#}^{\#}+$ & $\#^{\#}+\#$ \\
\hline-- & 0,0001 & $+^{-}-$ & $\frac{-}{t^{-}-}$ & $\begin{array}{l}-- \\
+-\end{array}$ & $\frac{-}{t^{-}+}$ & ${ }_{H}^{+H}+$ & $t_{H}^{H}+4$ & ${ }_{\#}^{H}+{ }_{H}^{H}$ \\
\hline
\end{tabular}

表中*キ附シタルモノハ死セルモノニシテ以下除ク

\section{4. เアセチール-ヒヨリンフ及レチラそンフ}

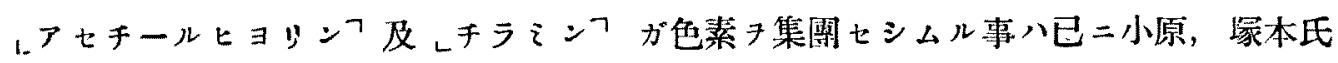

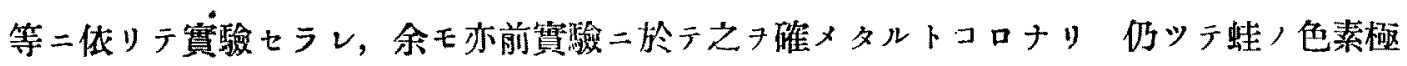

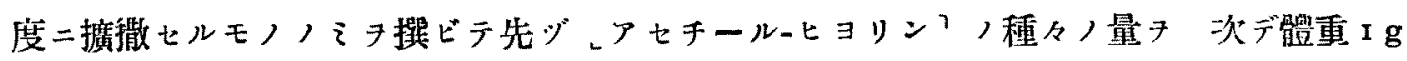
ニッキレチラそン゙， o,r mg チ注射セり(第 4 表公照).

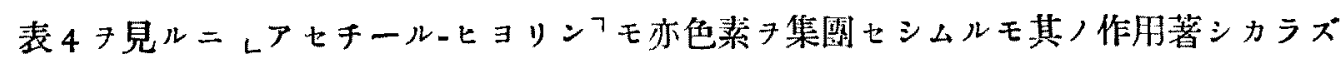

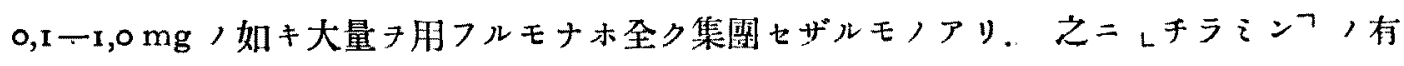
効量丹作用セシムル時ハ著シク集團ノアラハル、チ見ル。

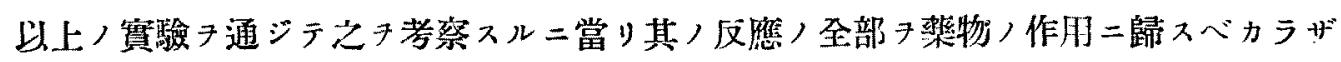
ルハ勿論ナレドモ其ノ變化一般二顯著ニシラ大部分ハえタ整物ノ作用ト見做スタ得ベシ.

\section{結諭}

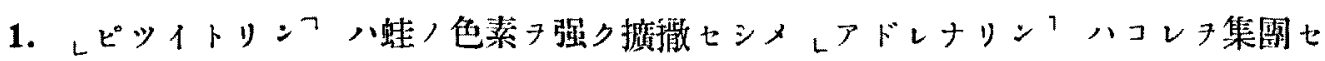


第 4 表

\begin{tabular}{|c|c|c|c|c|c|c|c|c|}
\hline \multirow{3}{*}{$\begin{array}{l}\text { 注射前 } \\
\text { >狀㑷 }\end{array}$} & \multirow{3}{*}{ 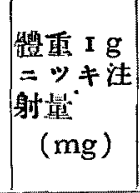 } & \multicolumn{7}{|c|}{ 泩射後ノ時間（時）及其ノ時ノ狀態 } \\
\hline & & \multicolumn{4}{|c|}{ レナチールーヒョリンフ } & \multicolumn{3}{|c|}{ レタミン } \\
\hline & & $\frac{I}{2}$ & I & 2 & 3 & $\frac{1}{2}$ & I & 2 \\
\hline-- & 1,0 & $\begin{array}{l}-- \\
+H\end{array}$ & $\frac{-+}{H^{+}+}$ & $H^{+}+$ & $H^{-+}+H^{*}$ & $\#^{+}$ & 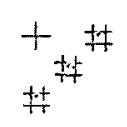 & ${ }_{\#}^{+}$ \\
\hline- & $0, \mathbf{r}$ & $\begin{array}{l}-- \\
++4\end{array}$ & $+^{-}+$ & $+^{-}+$ & $H^{+}{ }^{+}$ & $\begin{array}{l}+H \\
H^{H}\end{array}$ & $\begin{array}{l}+\# \\
\#\end{array}$ & ${ }_{\#}^{+}$ \\
\hline-- & 0,01 & -- & $+^{-}+$ & $+^{-}+$ & $+^{-}-$ & $H^{+}{ }^{H}$ & ${ }_{\#}^{\#}+{ }^{H}$ & $\begin{array}{l}H \\
H^{H}\end{array}$ \\
\hline${ }^{-}-$ & 0,001 & -- & ${ }^{-}-$ & ${ }^{-}-$ & -- & ${ }_{H^{+}}^{+}{ }^{H}$ & $\begin{array}{l}t_{H} \\
\#^{H}\end{array}$ & $\begin{array}{l}t+{ }_{t+} \\
t_{t+} \#\end{array}$ \\
\hline${ }^{-}-$ & $0,000 \mathrm{I}$ & ${ }^{-}-$ & $\begin{array}{l}-- \\
-+\end{array}$ & ${ }^{-}-$ & ${ }^{-}-$ & ${ }_{\#+}^{+}{ }_{H}^{H}$ & $\begin{array}{l}\# \# \\
\#\end{array}$ & ${ }_{\#}^{\#}+{ }^{H}$ \\
\hline
\end{tabular}

表中*キ附ンタルモノ八死セルモノニシテ以下除ク。

シメ前者二對シラ括抗的二作用ス.

2. ᄂピロカルピンフ，டチラミンフ及レアセチールーヒヨリン'八蛙ノ色素集團セシム。

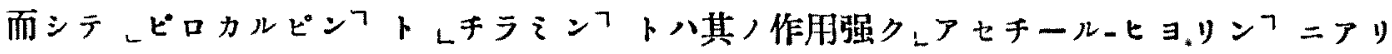
テハ其ノ作用最モ弱シ。

\section{引用書目}

I) G. Van Rynberk; Asher-Spiro, Ergebnisse d. Physiol. Jahrg. 5. Abteil. I u. 2.S. 476, Igว6.

2) Ecker u. Widerheim; Anatomie d. Frosches. Bd. 3, S. 514, 1904.

3) R. F. Fuchs; Handb. d. vergleich. Physiol. von Winterstein. BI. 3, r. Hälfte S. I9I4.

4) Steinach; Zentralb. f. Physiol. Bd. 5, S. 326. 189r.

5) Ehrmann; ebenda S. 377.

6) Biedermann; Pflïgers Arch. Bd. 51, S. 455, 1892.

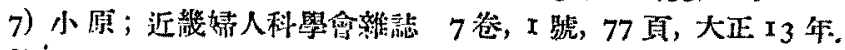

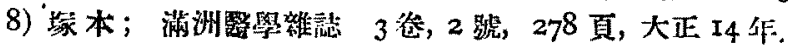

